\title{
COVID-19, mental health and ethnic minorities
}

\section{Katharine Smith, ${ }^{1,2}$ Kamaldeep Bhui, ${ }^{1,3,4}$ Andrea Cipriani (i) 1,2}

COVID-19 has evolved rapidly into a pandemic with global impacts. However, as the pandemic has developed, it has become increasingly evident that the risks of COVID-19, both in terms of infection rates and particularly of severe complications, are not equal across all members of society. While general risk factors for hospital admission with COVID-19 infection include age, male sex and specific comorbidities (eg, cardiovascular disease, hypertension and diabetes), there is increasing evidence that people identifying with Black, Asian and Minority Ethnic (BAME) groups ${ }^{i}$ have disproportionately higher risks of being adversely affected by COVID-19 in the UK and the USA. The ethnic disparities include overall numbers of cases, as well as the relative numbers of critical care admissions and deaths. ${ }^{1}$

In the area of mental health, for people from BAME groups, even before the current pandemic there were already significant mental health inequalities. ${ }^{2}$ These inequalities have been increased by the pandemic in several ways. The constraints of quarantine have made access to traditional face-to-face support from mental health services more difficult in general. This difficulty will increase pre-existing inequalities where there are challenges to engaging people in care and in providing early access to services. The restrictions may also reduce the flexibility of care offers, given the need for social isolation, limiting non-essential travel and closure of routine clinics. The service impacts are compounded by constraints on the use of non-traditional or alternative routes to care and support.

In addition, there is growing evidence of specific mental health consequences from significant COVID-19 infection, with increased rates of not only post-traumatic stress disorder, anxiety and depression, but also specific neuropsychiatric symptoms. ${ }^{3}$ Given the higher risks of mental

\footnotetext{
'Department of Psychiatry, University of Oxford, Oxford, UK

${ }^{2}$ Oxford Health NHS Foundation Trust, Warneford Hospital, Oxford, UK

${ }^{3}$ Queen Mary University of London, London, UK

${ }^{4}$ East London NHS Foundation Trust, London, UK
}

Correspondence to Professor Andrea Cipriani, Department of Psychiatry, University of Oxford, Oxford OX3 7JX, UK; andrea.cipriani@psych.ox.ac.uk illnesses and complex care needs among ethnic minorities and also in deprived inner city areas, COVID-19 seems to deliver a double blow. Physical and mental health vulnerabilities are inextricably linked, especially as a significant proportion of healthcare workers (including in mental health services) in the UK are from BAME groups.

Focusing on mental health, there is very little COVID-19-specific guidance on the needs of patients in the BAME group. The risk to staff in general healthcare (including mental healthcare) is a particular concern, and in response, the Royal College of Psychiatrists and NHS England have produced a report on the impact of COVID-19 on BAME staff in mental healthcare settings, with guidance on assessment and management of risk using an associated risk assessment tool for staff. 45

However, there is little formal guidance for the busy clinician in balancing different risks for individual mental health patients and treating appropriately. Thus, for example, an inpatient clinician may want to know whether a patient who is older, has additional comorbidities and is from an ethnic background, should be started on one antipsychotic medication or another, or whether treatments such as vitamin D prophylaxis or treatment and venous thromboembolism prevention should be started earlier in the context of the COVID-19 pandemic. While syntheses of the existing guidelines are available about COVID-19 and mental health, ${ }^{6} 7$ there is nothing specific about the healthcare needs of patients from ethnic minorities during the pandemic.

To fill this gap, we propose three core actions that may help:

1. Ensure good information and psychoeducation packages are made available to those with English as a second language, and ensure health beliefs and knowledge are based on the best evidence available. Address culturally grounded explanatory models and illness perceptions to allay fears and worry, and ensure timely access to testing and care if needed.

2. Maintain levels of service, flexibility in care packages, and personal relationships with patients and carers from ethnic minority backgrounds in order to continue existing care and to identify changes needed to respond to worsening of mental health.

3. Consider modifications to existing interventions such as psychological therapies and pharmacotherapy. Have a high index of suspicion to take into account emerging physical health problems and the greater risk of serious consequences of COVID-19 in ethnic minority people with pre-existing chronic conditions and vulnerability factors.

These actions are based on clinical common sense, but guidance in this area should be provided on the basis of good evidence. There has already been a call for urgent research in the area of COVID-19 and mental health ${ }^{8}$ and also a clear need for specific research focusing on the postCOVID-19 mental health needs of people from the BAME group. Research also needs to recognise the diverse range of different people, with different needs and vulnerabilities, who are grouped under the multidimensional term BAME, including people from different generations, firsttime migrants, people from Africa, India, the Caribbean and, more recently, migrants from Eastern Europe. Application of a race equality impact assessment to all research questions and methodology has recently been proposed as a first step in this process. ${ }^{2}$ At this early stage, the guidance for assessing risks of COVID-19 for health professionals is also useful for patients, until more refined decision support and prediction tools are developed. A recent Public Health England report on ethnic minorities and COVID $-19^{9}$ recommends better recording of ethnicity data in health and social care, and goes further to suggest this should also apply to death certificates. Furthermore, the report recommends more participatory and experience-based research to understand causes and consequences of pre-existing multimorbidity and COVID-19 infection, integrated care systems that work well for susceptible and marginalised groups, culturally competent health promotion, prevention and occupational risk assessments, and recovery strategies to mitigate the risks of widening inequalities as we come out of restrictions.

Primary data collection will need to cover not only hospital admissions but also data from primary care, linking information on mental health, COVID-19 and ethnicity. We already have research and specific guidance emerging on other risk factors, such as age and gender; now we also need to focus on an equally important aspect of vulnerability. As clinicians, we need to balance the relative risks for 
each of our patients, so that we can act promptly and proactively in response to their individual needs. ${ }^{10}$ For this, we need evidence-based guidance to ensure we are balancing every risk appropriately and without bias.

\section{FOOTNOTE}

i While we have used the term 'people identifying with BAME groups', we recognise that this is a multidimensional group and includes vast differences in culture, identity, heritage and histories contained within this abbreviated term.

Twitter Andrea Cipriani @And_Cipriani

Contributors KS drafted the editorial, and KB and AC revised it. All authors approved the final version of the manuscript.

Funding $\mathrm{KS}$ and $\mathrm{AC}$ are supported by the National Institute for Health Research (NIHR) Oxford Cognitive Health Clinical Research Facility. AC is also supported by an NIHR Research Professorship (grant RP-2017-08ST2-006), by the NIHR Oxford and Thames Valley Applied Research Collaboration and by the NIHR Oxford Health Biomedical Research Centre (grant BRC1215-20005).

Disclaimer The views expressed are those of the authors and not necessarily those of the UK National Health Service, the National Institute for Health Research or the UK Department of Health.

Competing interests $\mathrm{AC}$ has received research and consultancy fees from the Italian Network for Paediatric
Trials, the CARIPLO Foundation and Angelini Pharma, outside the submitted work.

Patient consent for publication Not required.

Provenance and peer review Not commissioned; internally peer reviewed.

This article is made freely available for use in accordance with BMJ's website terms and conditions for the duration of the covid-19 pandemic or until otherwise determined by BMJ. You may use, download and print the article for any lawful, non-commercial purpose (including text and data mining) provided that all copyright notices and trade marks are retained.

(C) Author(s) (or their employer(s)) 2020. No commercial re-use. See rights and permissions. Published by BMJ.

\section{Check for updates}

To cite Smith K, Bhui K, Cipriani A. Evid Based Ment Health 2020;23:89-90.

Received 8 July 2020

Accepted 9 July 2020

Published Online First 17 July 2020

Evid Based Ment Health 2020:23:89-90.

doi:10.1136/ebmental-2020-300174

ORCID iD

Andrea Cipriani http://orcid.org/0000-0001-5179-8321

\section{REFERENCES}

1 Khunti K, Singh AK, Pareek M, et al. Is ethnicity linked to incidence or outcomes of covid-19? BMJ 2020;369:m1548
2 Smith S, Gilbert S, Ariyo K, et al. Multidisciplinary research priorities for the COVID-19 pandemic. Lancet Psychiatry 2020;7:e40.

3 Rogers JP, Chesney E, Oliver D, et al. Psychiatric and neuropsychiatric presentations associated with severe coronavirus infections: a systematic review and metaanalysis with comparison to the COVID-19 pandemic. Lancet Psychiatry 2020;7:611-27.

4 COVID-19: Guidance on risk mitigation for BAME staff in mental healthcare settings. Available: https:// www.rcpsych.ac.uk/about-us/responding-to-covid-19/ responding-to-covid-19-guidance-for-clinicians/riskmitigation-for-bame-staff [Accessed 7 July 2020].

5 Risk reduction framework for NHS staff at risk of COVID-19 infection. Available: https://www.fom.ac.uk/ wp-content/uploads/Risk-Reduction-Framework-forNHS-staff-at-risk-of-COVID-19-infection-12-05-20.pdf [Accessed 7th Jul 2020].

6 Smith K, Ostinelli E, Cipriani A. Covid-19 and mental health: a transformational opportunity to apply an evidence-based approach to clinical practice and research. Evid Based Ment Health 2020a;23:45-6.

7 COVID-19: guidance for clinicians. Available: https:// www.rcpsych.ac.uk/about-us/responding-to-covid19/responding-to-covid-19-guidance-for-clinicians [Accessed 7th Jul 2020].

8 Holmes EA, O'Connor RC, Perry VH, et al. Multidisciplinary research priorities for the COVID-19 pandemic: a call for action for mental health science. The Lancet Psychiatry 2020;7:547-60.

9 PHE. Beyond the data: understanding the impact of COVID-19 on BamE groups, 2020. Available: https:// assets.publishing.service.gov.uk/government/uploads/ system/uploads/attachment_data/file/892376/COVID_ stakeholder engagement_synthesis beyond the data.pdf [Accessed 7th Jul 2020].

10 Cipriani A, Tomlinson A. Providing the most appropriate care to our individual patients. Evid Based Ment Health 2019:22:1-2. 